\title{
Hydraulic study on scouring downstream of Funagira Dam spillway apron (Japan)
}

\author{
Y. Kitamura \\ Chigasaki Research Institute, J-POWER (Electric Power Development Co., Ltd.), Chigasaki, Japan \\ S. Takagi \\ Funagira Construction Office, J-POWER (Electric Power Development Co., Ltd.), Hamamatsu, Japan
}

\begin{abstract}
Funagira Dam is a concrete gravity dam having a height of $24.50 \mathrm{~m}$ and a dam crest length of $220.00 \mathrm{~m}$, and is located approximately $30 \mathrm{~km}$ upstream from the mouth of the Tenryu River. The Funagira Dam is owned by the Ministry of Agriculture, Forestry and Fisheries, Shizuoka Prefecture, and Electric Power Development Co., Ltd. (J-POWER), and its objectives include power generation and supply of agricultural water, public water, and industrial water. For energy dissipation, the downstream area of the dam was designed as a hydraulic jump-type dissipater using bed protection blocks. The dam has experienced several large storm events in the 40 years after its completion. The protection blocks were damaged and the scouring downstream of the dam began soon after completion. About 6,300 tetrapods were added stage by stage to the bottom. In recent times (2011), however, flood events have been more intense and of longer duration, with maximum spillway releases of up to approximately $6,396 \mathrm{~m}^{3} / \mathrm{s}$. This resulted in increased scouring at the foot of the dam. Emergency measures were taken just downstream of the dam apron from 2011 to 2013. The scouring process is a function of several variables, such as water discharge, water level downstream, bed protection, bed materials, transport, morphological riverbed conditions, and gate operations. Experimental studies with field observations, mathematical model tests, and vertical 2-dimensional and fully 3-dimensional hydraulic scale model tests have been carried out to examine the scouring processes and to determine long-term measures. These studies indicate that scouring was caused by a horizontal secondary flow with non-uniform discharge releases, and by changing the types of hydraulic jump because of long-term morphological riverbed changes. The study especially indicates that severe scouring would occur not only for extreme planned discharge but also for small discharges, because of the downstream water level of the dam.
\end{abstract}

\section{INTRODUCTION}

Energy dissipation downstream of the dam has to be sufficient to reduce the stream power and to pass the flood discharge safely. Various dissipation methods are used in places where the excess hydraulic energy could cause such damage as erosion of tail water channels, abrasion of hydraulic structures, generation of tail water waves, or scouring. Scouring downstream of dam and spillway structures is a major topic in relation to hydraulic structures that foresee the production of flood discharge.

Funagira Dam was built at the most downstream area of the Tenryu River in 1977 (Figure 1). The dam is a concrete gravity dam, and is $24.5 \mathrm{~m}$ high and $220 \mathrm{~m}$ long, with 9 large spillway gates (Figure 2 ). The spillway facilities were designed to handle the planned discharge of up to $11,130 \mathrm{~m}^{3} / \mathrm{s}$ under a gross head of $10 \mathrm{~m}$ to $18 \mathrm{~m}$. For energy dissipation, the area downstream of the dam was designed as a hydraulic jump-type dissipater using bed protection blocks (Figure 3).

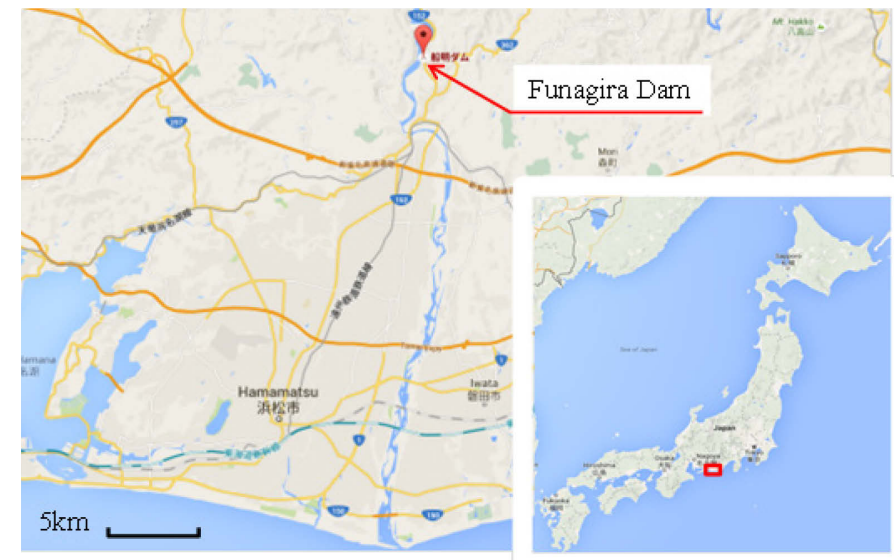

Figure 1. Location map of Funagira Dam

The dam has experienced several large storm events during the 40 years after completion. The protection blocks were damaged and the scouring downstream of the dam began soon after completion. 
About 6,300 tetrapods were added in stages to the bottom. In recent times, however, flood events were more intense and of longer duration, with maximum spillway releases of up to approximately $6,396 \mathrm{~m}^{3} / \mathrm{s}$. This resulted in increased scouring at the foot of the dam. Emergency measures were built just downstream of the dam apron from 2011 to 2013.

The scouring process is caused by several variables, such as water discharge, water level downstream, bed protection, bed materials, sediment transport, morphological riverbed conditions, and gate operations.

In this paper, an experimental study with field observations, mathematical model tests, and vertical 2dimensional and fully 3-dimensional hydraulic scale model tests were carried out to examine the scouring processes and to determine long-term measures.

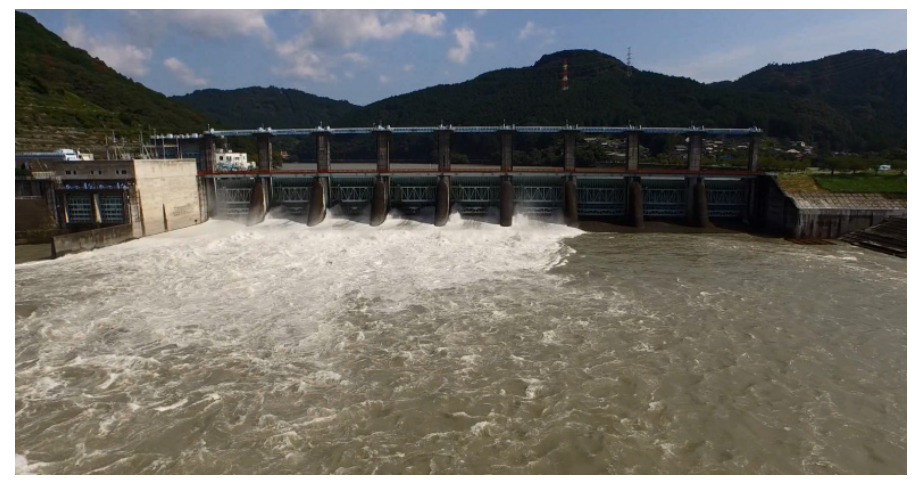

Figure 2. General view of Funagira Dam (Sep. 4, 2015)

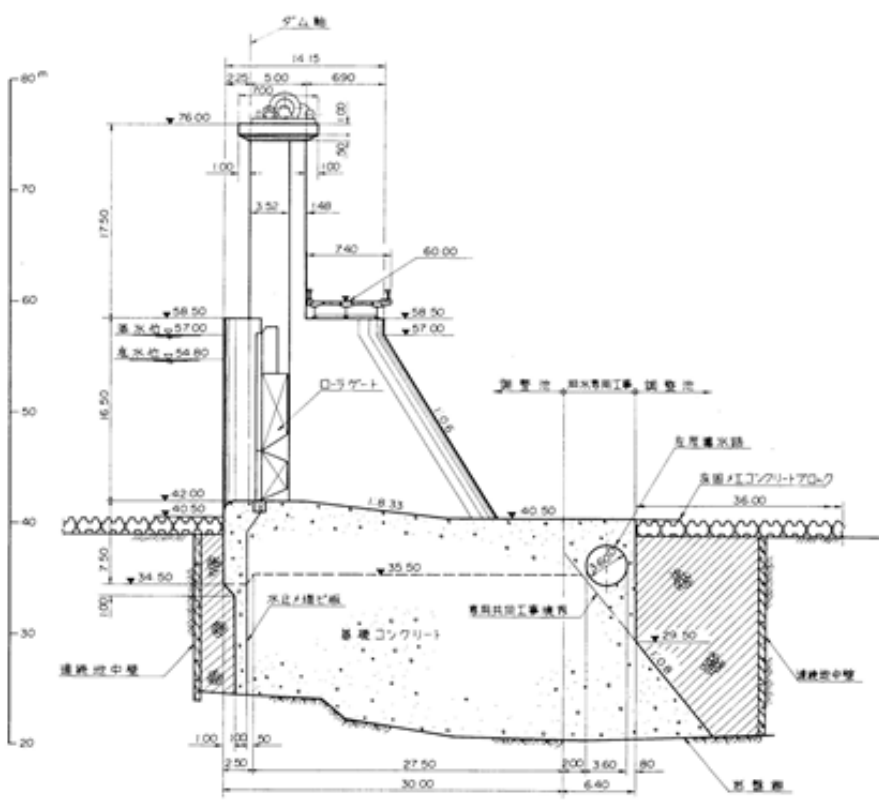

Figure 3. Funagira Dam standard cross section at left side of river

\section{SCOURING SITUATION AND MEASURES}

In June 1977, immediately after completion of the dam, the first flood was discharged using a few of the gates, with a maximum outflow rate of 2,134 $\mathrm{m}^{3} / \mathrm{s}$, which was not so large. However, almost all the consolidation blocks (5-t blocks) forming the downstream bottom at a height of $40.5 \mathrm{~m}$ were damaged during the flood discharge. The riverbed at Gate 6, just downstream of the dam, was scoured by a volume of approximately $90,000 \mathrm{~m}^{3}$, with a maximum depth of approximately $10 \mathrm{~m}$. Figure 4 and Table 1 show how the riverbed was scoured and how scouring mitigation measures have been taken until now, since the completion of Funagira Dam (1977).

Table 1. History of scouring and its measures

\begin{tabular}{|c|c|}
\hline Period & Situation of scouring and its measures \\
\hline $\begin{array}{l}1978 \\
-1992\end{array}$ & $\begin{array}{l}* \text { Placed } 6,300 \text { tetrapods }(5-\mathrm{t}, 6.3-\mathrm{t}) \text { as bed protec- } \\
\text { tion work } \\
* \text { Switched discharge operation from pyramid style } \\
\text { to modified pyramid style (front center gates were } \\
\text { opened equally). } \\
* \text { Largest discharged floods: } 8,700 \mathrm{~cm} \text { in } 1982 \text {, and } \\
8,613 \mathrm{~cm} \text { in } 1983 \\
* \text { Additional tetrapods }(6.3-\mathrm{t}) \text { in jointed manner } \\
\text { with cables between } 1990 \text { to } 1992 \\
* \text { Changed discharge operation to partially equal } \\
\text { style (Gates } 4 \text { to } 8 \text { with equal opening until the } \\
\text { flow rate of } 3,000 \mathrm{~cm} \text { ) }\end{array}$ \\
\hline $\begin{array}{l}1992 \\
-2003 \\
\end{array}$ & $\begin{array}{l}\text { * Stable with slight morphological changes in each } \\
\text { year and no particular measure }\end{array}$ \\
\hline $\begin{array}{l}2003 \\
-2011\end{array}$ & $\begin{array}{l}* \text { Scoured riverbed gradually in front of dam spill- } \\
\text { way } \\
* 15 \mathrm{~m} \text { of riverbed scoured locally near dam (chan- } \\
\text { nel syphon hollowed water) foundation in front of } \\
\text { Gates } 3 \text { and } 4 \text { due to the large and long period of } \\
\text { discharge }(153 \text { days and } 6,396 \mathrm{~cm}) \text {. }\end{array}$ \\
\hline $\begin{array}{l}2011 \\
-2013\end{array}$ & $\begin{array}{l}* \text { Filled with underwater concrete with filter-unit } \\
\text { above scoured foundation (Gates } 3 \text { and } 4 \text { ) between } \\
\text { September } 2011 \text { and May } 2012 \\
* \text { Additional measures with } 836 \text { tetrapods (12.5-t } \\
\text { type) in front of Gates } 1 \text { to } 5 \text { between August and } \\
\text { October } 2012 \text { and March and April } 2013\end{array}$ \\
\hline $\begin{array}{l}2013 \\
-2015\end{array}$ & $\begin{array}{l}* \text { Reviewed long-term measures for selection and } \\
\text { control methods in the technical workshop on } \\
\text { scouring downstream of the Funagira Dam and the } \\
\text { follow-up committee }\end{array}$ \\
\hline 2015 & $\begin{array}{l}\text { * Started long-term mitigation work in October } \\
2015 \\
\text { * Planned construction work to be completed in } \\
\text { May } 2018\end{array}$ \\
\hline
\end{tabular}

Between 2010 and 2011, a large flood $\left(6,396 \mathrm{~m}^{3} / \mathrm{s}\right.$ in September 21, 2011) was discharged continuously and for a long period (153 days), scouring the riverbed to the waterway foundation bedrock just downstream of Gates 3 and 4. In response to this, mitigation work was carried out at the waterway foundation; in addition, bed protection blocks (12.5-t tetrapods) were placed as emergency measures on the left bank, just downstream of Gates 1 to 5 , in May 2013 (see Figure 5). 

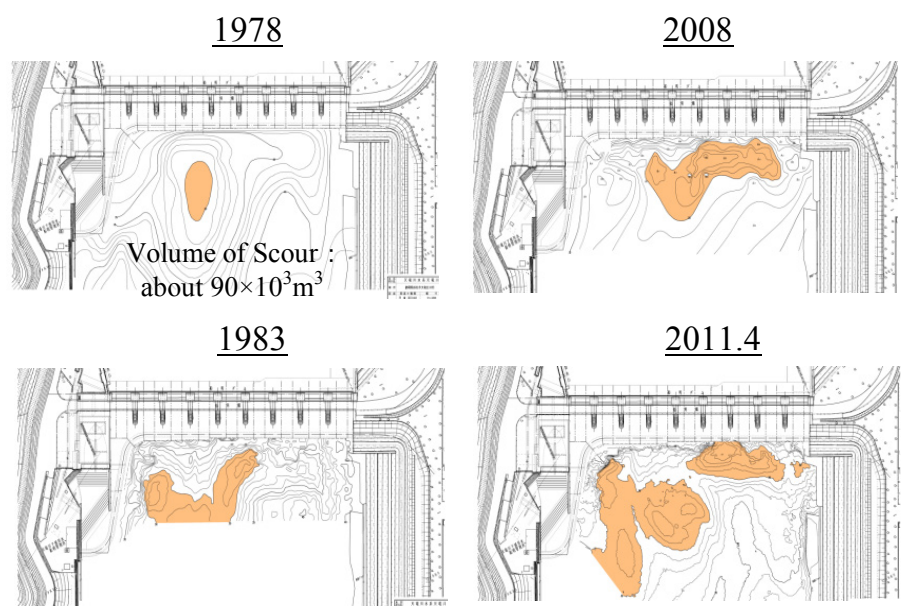

$\underline{1990}$

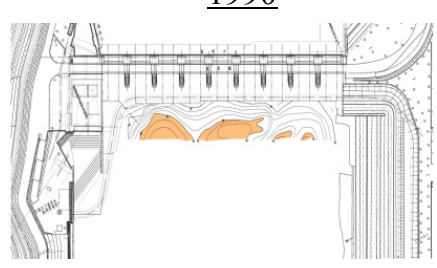

*Color area is lower than EL.30m

$\underline{2011.5}$

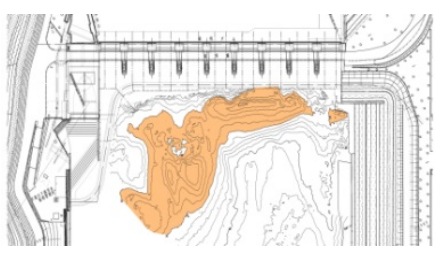

Figure 4. Morphological change in front of Funagira Dam (1978-2011)

The downstream area of the dam in 2011 was scoured by a volume of approximately $230,000 \mathrm{~m}^{3}$, with a maximum depth of approximately $13 \mathrm{~m}$, for a riverbed height of EL $39.0 \mathrm{~m}$.

Plane
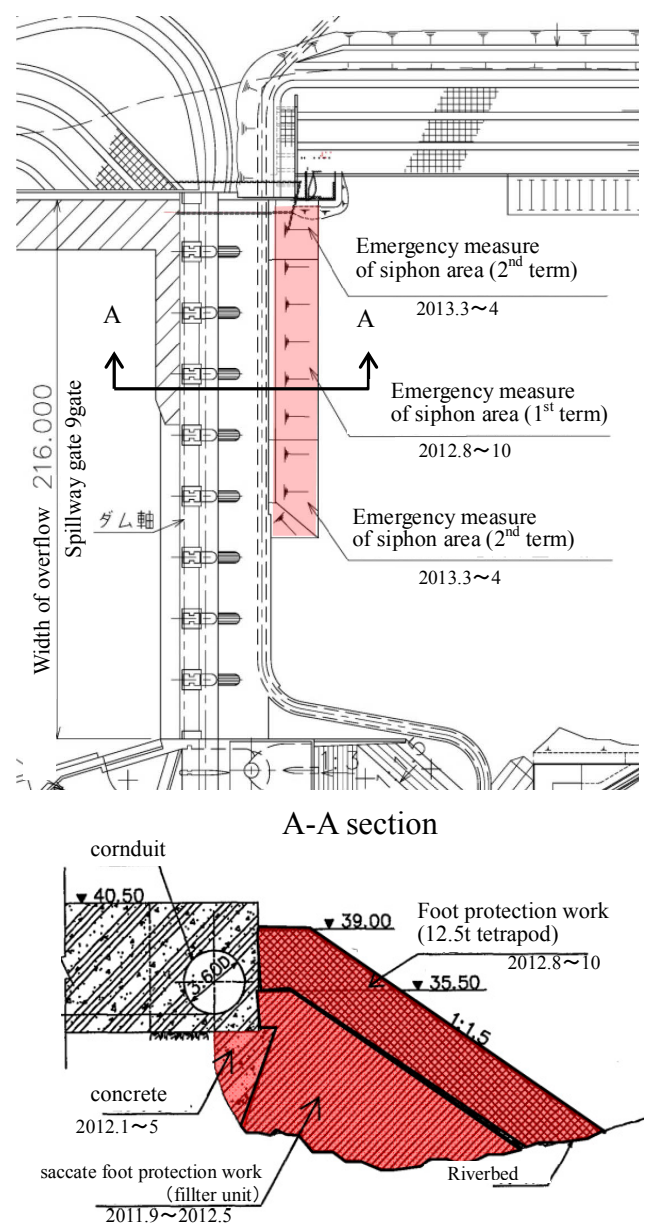

Figure 5. Plane and cross section of emergency measures

\section{STUDY OF SCOURING FACTORS}

To investigate why and how the riverbed downstream of Funagira Dam was scoured, we have studied, using hydraulic scale models, the morphological changes in the riverbed, to examine the scouring processes and to determine long-term measures. The study uses field observations, mathematical model tests and several hydraulic scale models. Also, two vertical 2-dimensional partial models (Figure 6) with a scale of 1/50 and also a fully 3 -dimensional model with a scale of $1 / 50$ of the movable riverbeds at and around the dam $1.5 \mathrm{~km}$ upstream and downstream (Figure 7) were used. As a result, we have identified the factors that caused scouring immediately after the dam was completed and why the riverbed was scoured further.

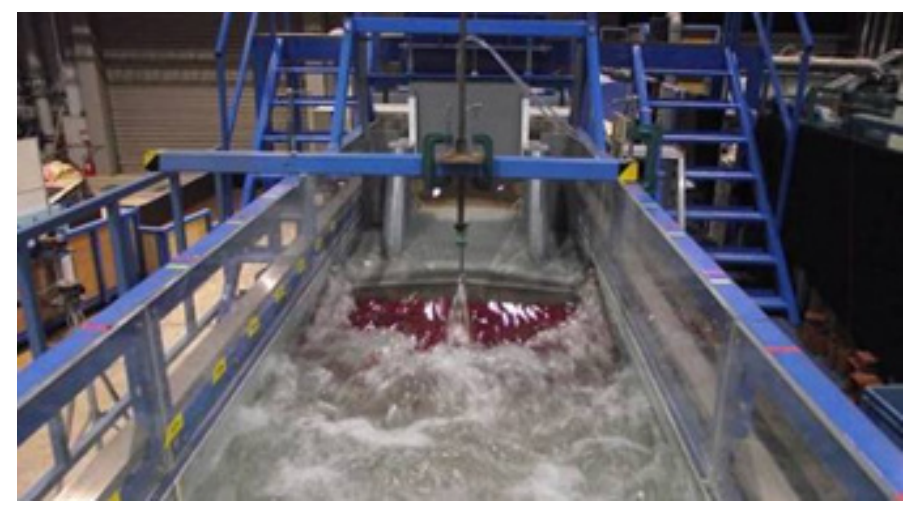

Figure 6. Vertical 2-dimensional partial model

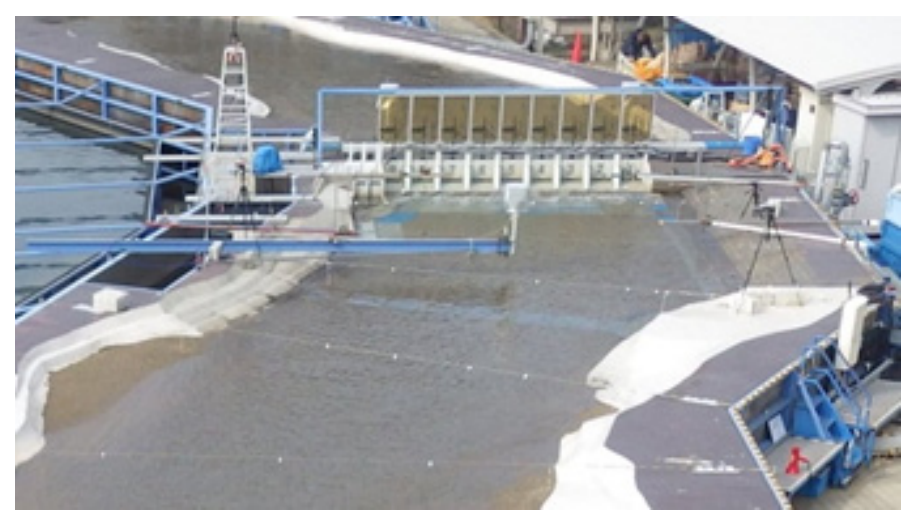

Figure 7. Fully 3-dimensional model

\subsection{Scouring of bedrock}

While Funagira Dam was being constructed, bedprotection blocks were placed as a measure against scouring on the riverbeds, where gravel was present immediately downstream of Gates 1 to 5. Meanwhile, with no fear of scouring, no such blocks were placed immediately downstream of Gates 6 to 8 near the right bank, where the bedrock (black schist) was exposed. However, according to the results of the depth measurements conducted in 1978, the exposed bedrock on the right bank was significantly scoured 
by discharged water immediately after the dam was completed.

Even though the scoured bedrock could not be assessed quantitatively, it can be thought that it was caused by fluid forces and stones that hit and scratched the jointed bedrock.

\subsection{Removal of bed-protection blocks and scouring of gravel bed by swirling flow}

As described above, the bed-protection blocks were not evenly placed across the river, but placed along areas where bedrock was not apparent (Figure 8). Therefore, it can be imagined that the bed-protection blocks placed along the edges of the subject area were removed by irregular water flows and unstable hydraulic jump, caused by an uneven riverbed along the boundary between the exposed bedrock and the gravel/bed-protection blocks.

The experiments using the vertical 2-dimensional hydraulic scale model, where a boundary was reproduced between the bedrock and gravel, showed that, even though the bed-protection blocks were stable when they were entirely evenly placed, a large morphological change was observed and the damage to the blocks was expanded in front of Gate 7 (Figure 9).

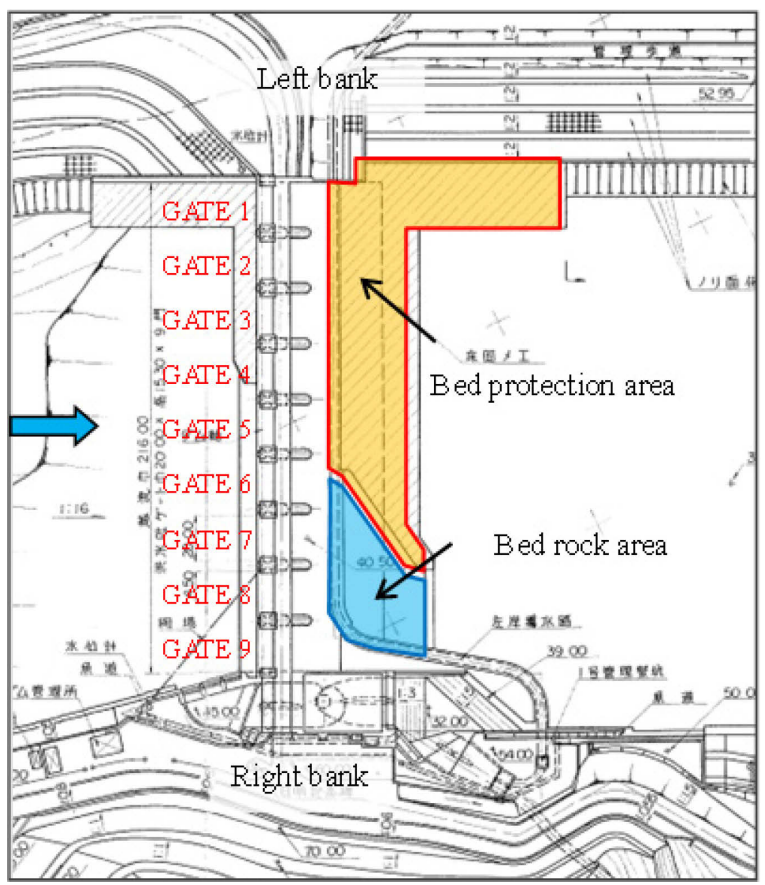

Figure 8. Area of original bed protection measures

Accordingly, it can be thought that some bedprotection blocks were removed and the gravel around them was scoured immediately after the dam was completed. This would then reduce the engaging effect of adjacent blocks, and then the blocks were further removed in a wide area, eventually losing the function of protecting the bedrock with the blocks.

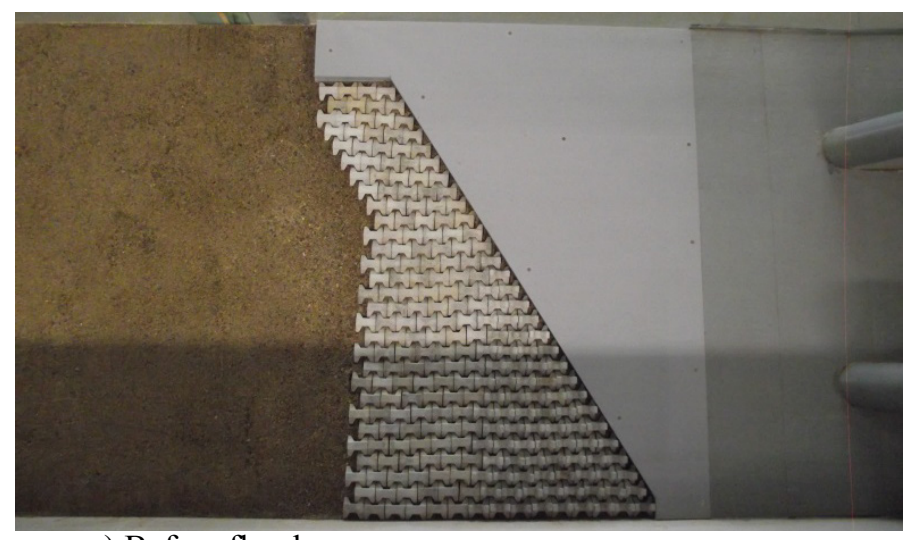

a) Before flood

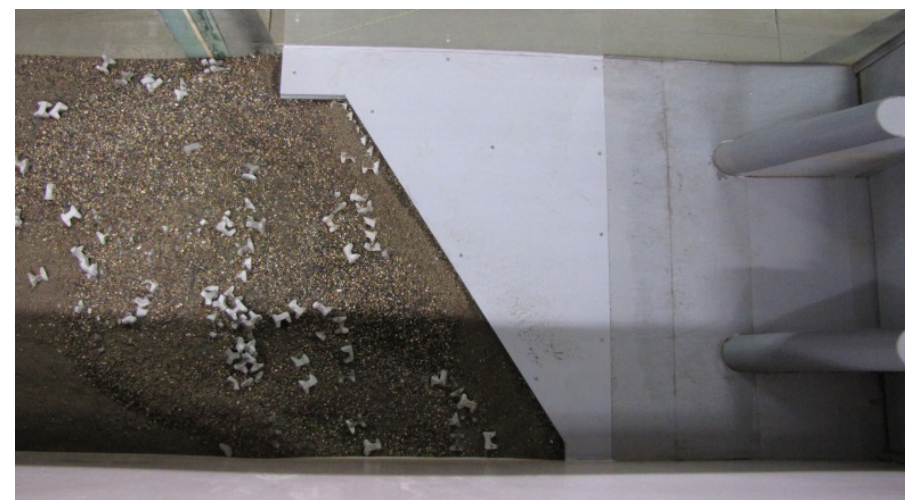

b) After flood

Figure 9. Model test for stability about original bed protection in front of Gate 7

\subsection{Effect of horizontal swirl flow}

In the flood events experienced after the dam was completed, several floods were discharged from the gates in a pyramid style (consecutive gate openings) during 1978 and 1982. After two large floods, we changed the gate operation in a partially equivalent procedure in 1983 (Figure 10). Even in the case of following this equivalent procedure, the rates of water discharged on both left and right sides differed, still generating a plane horizontal swirl flow in an area near both the left and right banks downstream of the gates from which no water was discharged (dead water region).

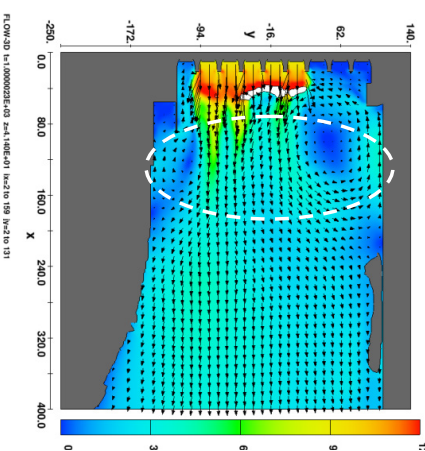

Partial equal gate operation

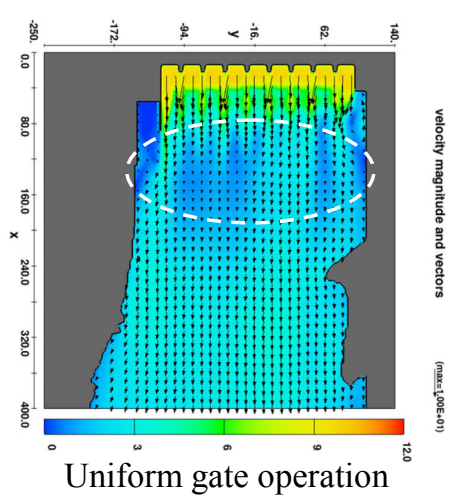

Uniform gate operation
Figure 10. Difference of pyramid and partial equivalent procedures of gate operations until $3,000 \mathrm{~m}^{3} / \mathrm{s}$ 
Downstream of Funagira Dam, in particular, the horizontal swirl flow around the left bank was larger than around the right bank. Figure 11 shows the flow conditions downstream of Funagira Dam computed by a 3-dimensional free surface mathematical model. The partially equivalent procedure generates a huge horizontal swirl flow around the left bank of the dam.

The experiments using the 3-dimensional model showed that the horizontal swirl flow proceeded upstream towards the left bank, changed direction at the lower edge of the apron, and then flowed parallel to the dam axis (Figure 12). The water flowing parallel to the dam axis formed a diagonally downward flow when joining the flow of water discharged from the gates, creating a critical flow for the protection blocks and scouring on the riverbed unlike a normal hydraulic jump.

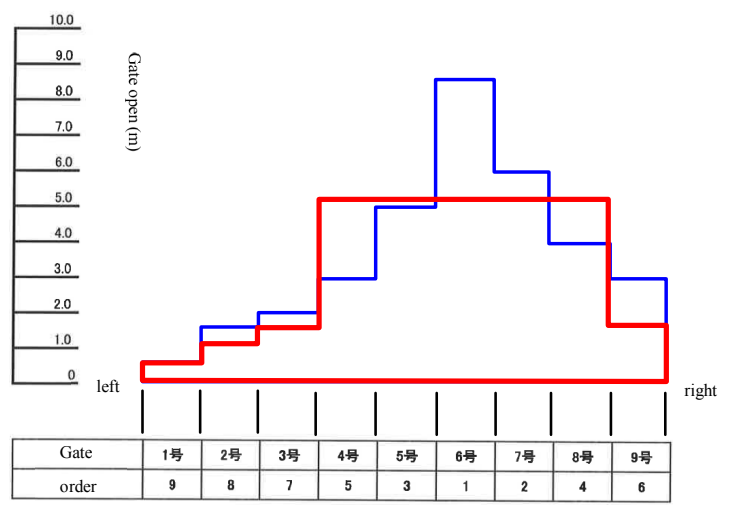

Pyramid style (1978 1982)

Partial equivalent style (1983 2014)

Figure 11. Comparison of flow condition with gate operations

\subsection{Effect due to the reduced water level downstream of the dam}

From the completion of the dam (in 1977) until the end of 1985, the water level lowered by approximately $10 \mathrm{~cm}$ per year. The water level still keeps on lowering, even though its rate is moderated, approximately a few centimeters per year since the 1990s. Experiments using the vertical 2-dimensional hydraulic scale model allowed to investigate the relationship between the rate of water discharged from the gates and the downstream water level, as well as how water was discharged from the gates at that time.

For a constant discharge rate, different types of hydraulic jump are formed as (1) an underwater flow, (2) a submerged flow, (3) a free flow, and (4) a drop flow (overflow), according to the downstream water level. The riverbed was mostly scoured in the presence of an underwater flow type (Figure 13).

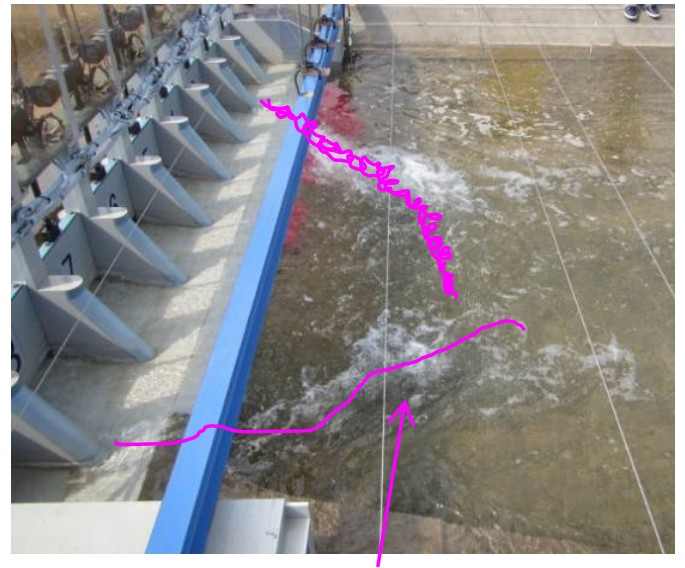

Position of hydraulic jump

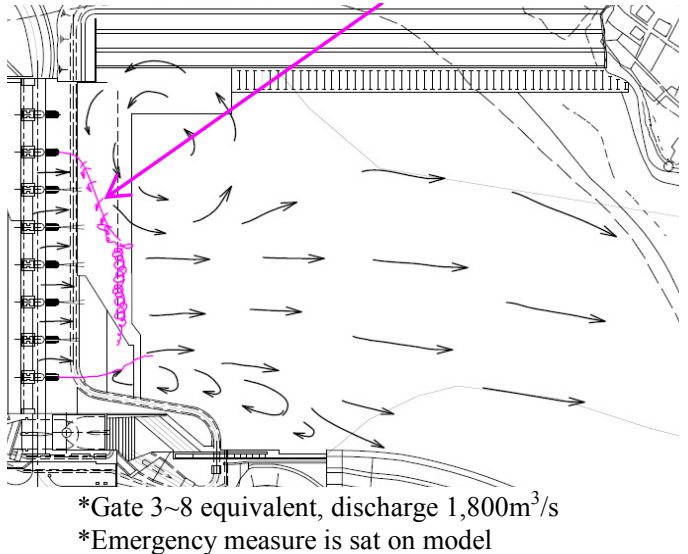

Figure 12. Flow regime of partial equivalent gate style

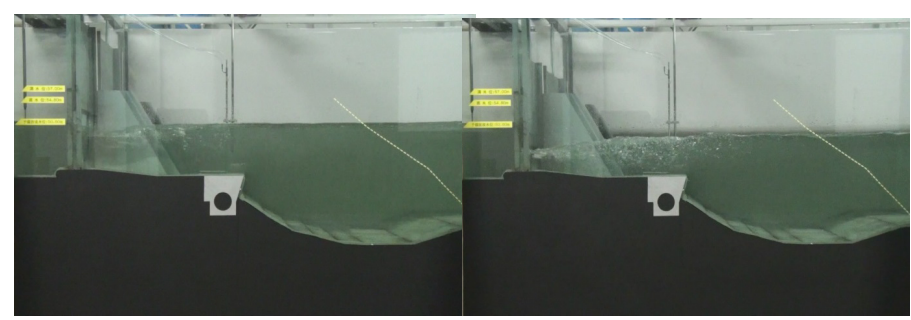

Underwater flow

Submerged flow

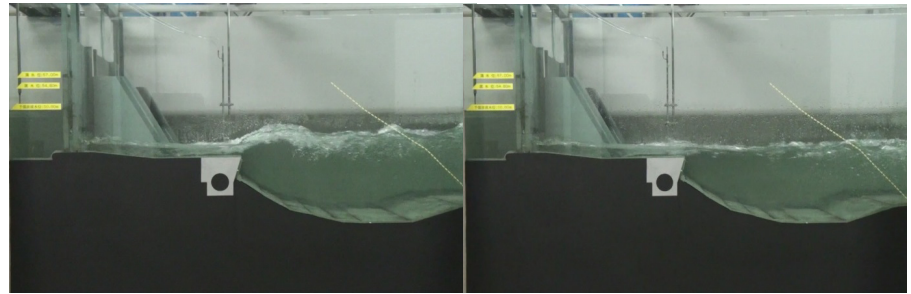

Free flow

Drop flow (Overflow)

Figure 13. Types of hydraulic jump in front of Gate 7 following different downstream water levels 
Figure 14 summarizes the different types of hydraulic jump as a function of the downstream water level and as a function of the Gate 6 discharge rate. It shows that the lower the downstream water level, the more different types of hydraulic jump are appearing. Also, drop flow appears in the case of the lowest downstream water level.
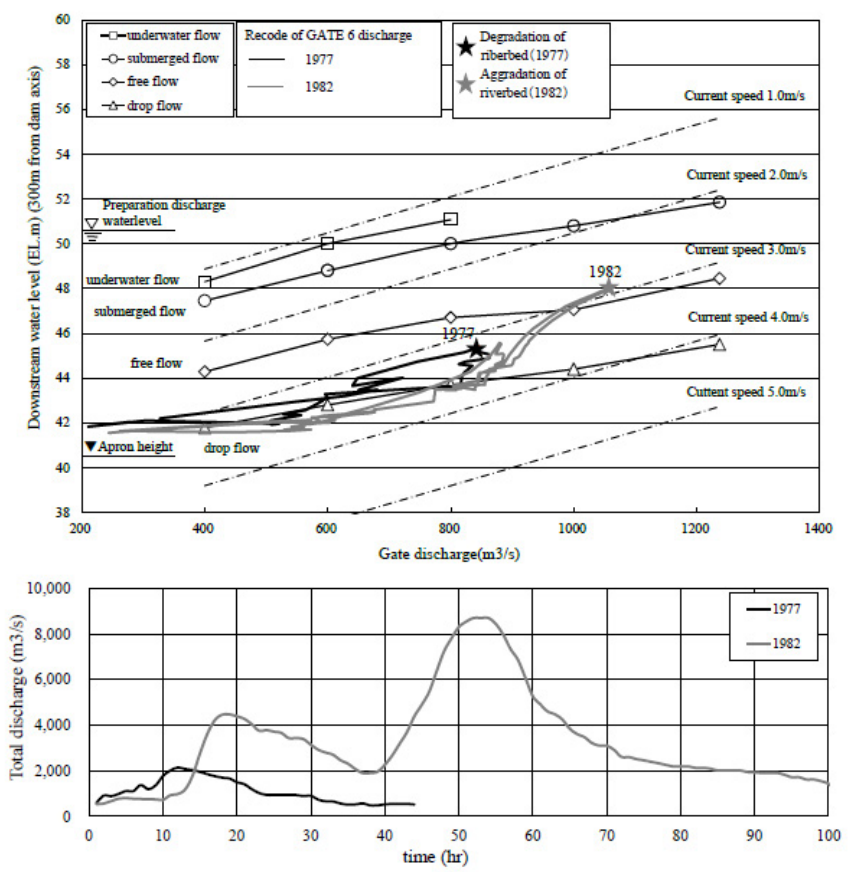

Figure 14. Types of hydraulic jump following the downstream water level and for different Gate 6 discharge rates

The flood of $2,134 \mathrm{~m}^{3} / \mathrm{s}$ in 1978 and the largest flood of $8,700 \mathrm{~m}^{3} / \mathrm{s}$ in 1982 generated similar types of hydraulic jump until $800 \mathrm{~m}^{3} / \mathrm{s}$ discharge of Gate 6 in the figure. It means that the downstream water level is low at the beginning of discharge with any class of flood discharge, and that it facilitates scouring of the riverbed at the initial discharge operation. It is the reason that Funagira Dam was seriously scoured during the small flood in 1978.

The reduction of the downstream water level can also cause water to flow down in a stepwise manner, which can facilitate scouring of the riverbed. It is one of the factors that generates scouring in the riverbed downstream.

\section{EMERGENCY MEASURES AND LONG- TERM MEASURES}

\subsection{Stability of emergency measures in 2013}

We have investigated the stability of the emergency measures (consolidation work using 12.5-t type tetrapods) taken from 2012 to 2013 through the results of monitoring conducted locally and the experiments using hydraulic scale models. In the investigation, we found that some tetrapods were moved after water was discharged in a partially equivalent procedure. On the other hand, when discharging using a full-gate equivalent procedure, sand was built up and kept relatively stable with a discharge in a range from approximately $7,200 \mathrm{~cm}$ to $8,000 \mathrm{~cm}$. However, when the discharge exceeded $8,000 \mathrm{~m}^{3} / \mathrm{s}$, that is, the water flowed freely, sand was scoured downstream of Gates 1 to 4 and of Gate 9. Particularly, the left and right banks were largely scoured (downstream of Gates 1, 2, and 9) (Figure 15).

In the present situation with emergency measures, the left and right banks can be scoured when water is discharged, even in a full-gate equivalent procedure, at a rate of a minimum of $8,000 \mathrm{~cm}$. So we have determined that some permanent mitigation measures (hereinafter referred to as "long-term measures") must be implemented as quickly as possible to obtain sound protection.

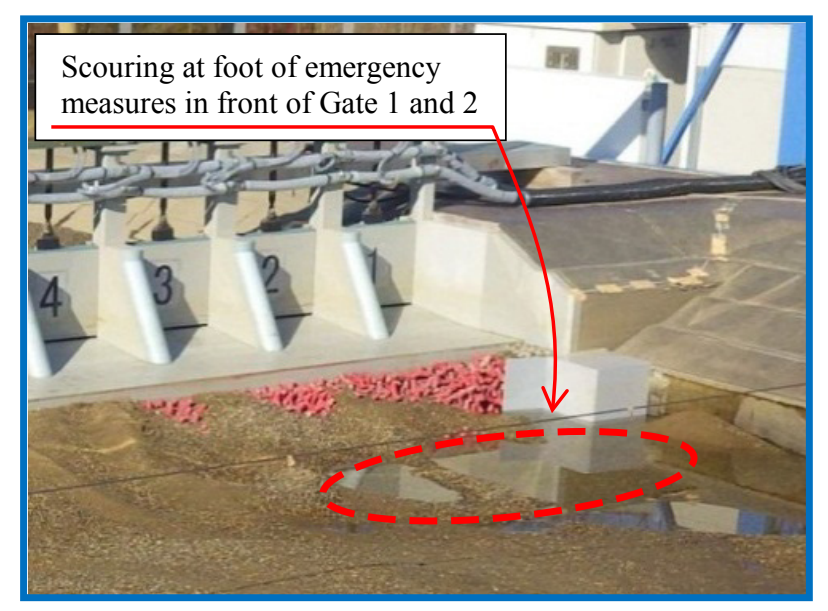

Figure 15. Stability of emergency measure in 2013 after design discharge of $11,130 \mathrm{~m}^{3} / \mathrm{s}$ with equivalent procedure of gate operation

\subsection{Design of long-term measures}

The following shows the guidelines for establishing long-term measures, based on an enhancement of the stability of the emergency measures.

(1) To reduce possible horizontal swirl flow that can facilitate scouring on the riverbed, switch the gate discharging method from the currently adopted "partially equivalent procedure" to "full-gate equivalent procedure."

(2) Carry out measures for preventing scouring on the bedrock on the right bank, above the bedrock, to obtain the same bottom rugosity in the lateral direction and to allow laterally uniform flow.

(3) Take some measures to prevent the riverbed downstream of the dam from being lowered and scoured for a long period.

(4) When switching the gate discharging operation, be sure to take some measures as required so that the flow of water along the left and right banks and the shape of the riverbed do not change. 


\section{STUDY BY USING HYDRAULIC SCALE MODEL TESTS}

\subsection{Properties of long-term measures}

To establish long-term measures, we have studied a "riverbed recovery plan" that is similar to the original riverbed, and a "riverbed maintenance plan" for carrying out reinforcement based on the shape of the riverbed after the emergency measures were taken, and for expanding the areas to which the measures will be implemented. Through the study, we have taken into account the present situation where the downstream water level is lowered, and focused on (including maintenance and control) how the longterm measures can be comprehensively satisfied, based on the experiments using hydraulic scale models. Figure 16 shows the "riverbed recovery plan" and the "riverbed maintenance plan."

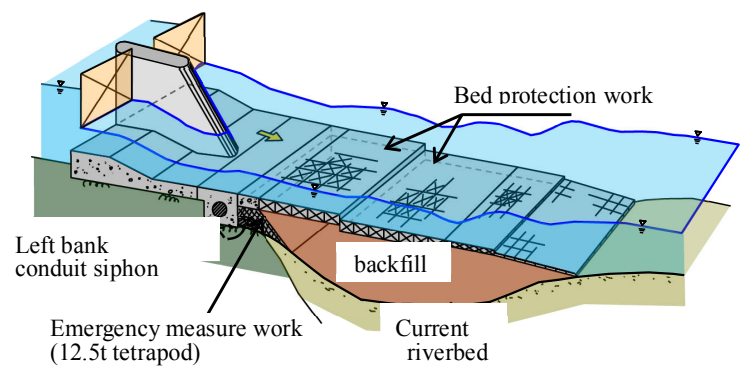

(a) Recovery plan

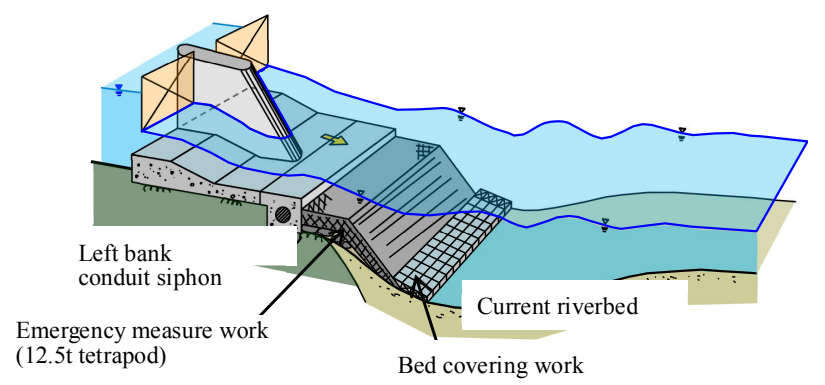

(b) Maintenance plan

Figure 16. Possible plans of long-term measures

According to the results of the experiments, both riverbed plans reduced scouring potential during extreme flooding. The measures led to stable results, meaning that they were safe against scouring immediately downstream of the dam. During free flow discharge, the water flow was biased toward the left bank by the sedimentation on the right bank, resulting in local scouring along the left bank. Therefore, although the blocks placed along the left bank downstream of the dam were partially removed, it was considered that the impact was local and did not expand further (Figure 17 and Figure 18).
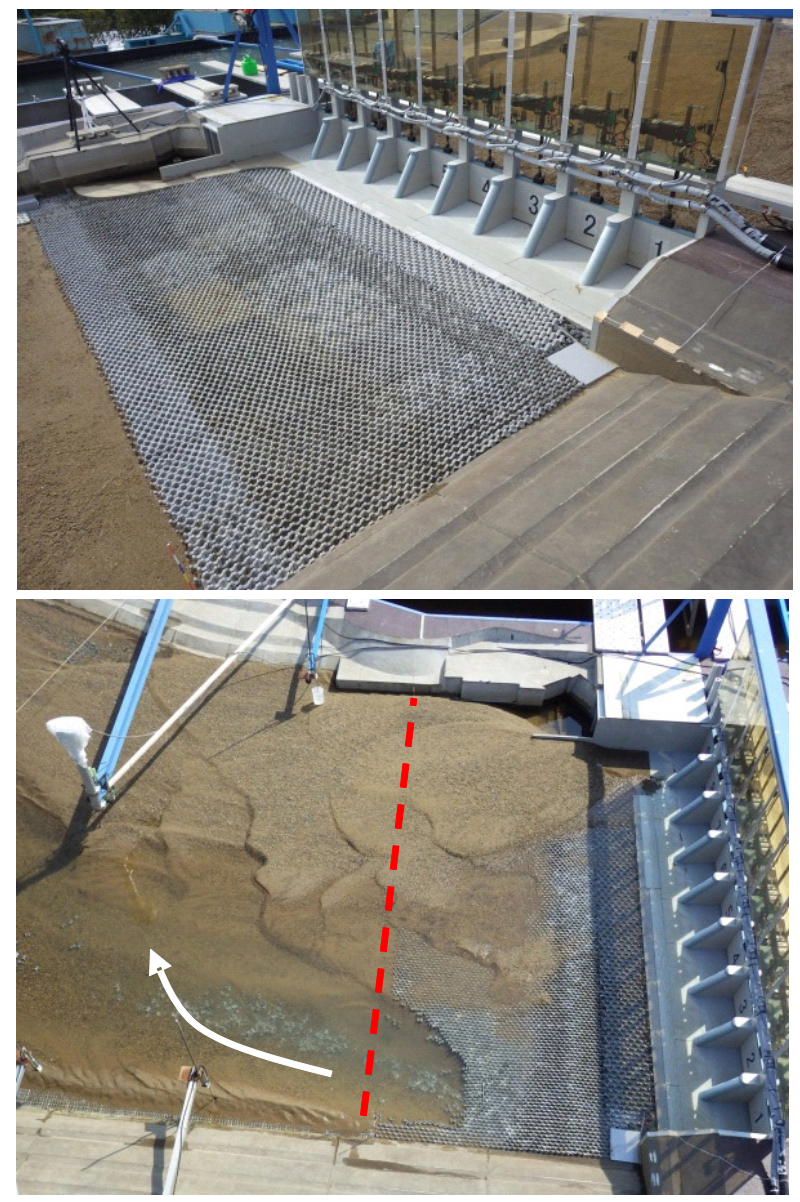

Figure 17 . Stability of recovery plan after design flood
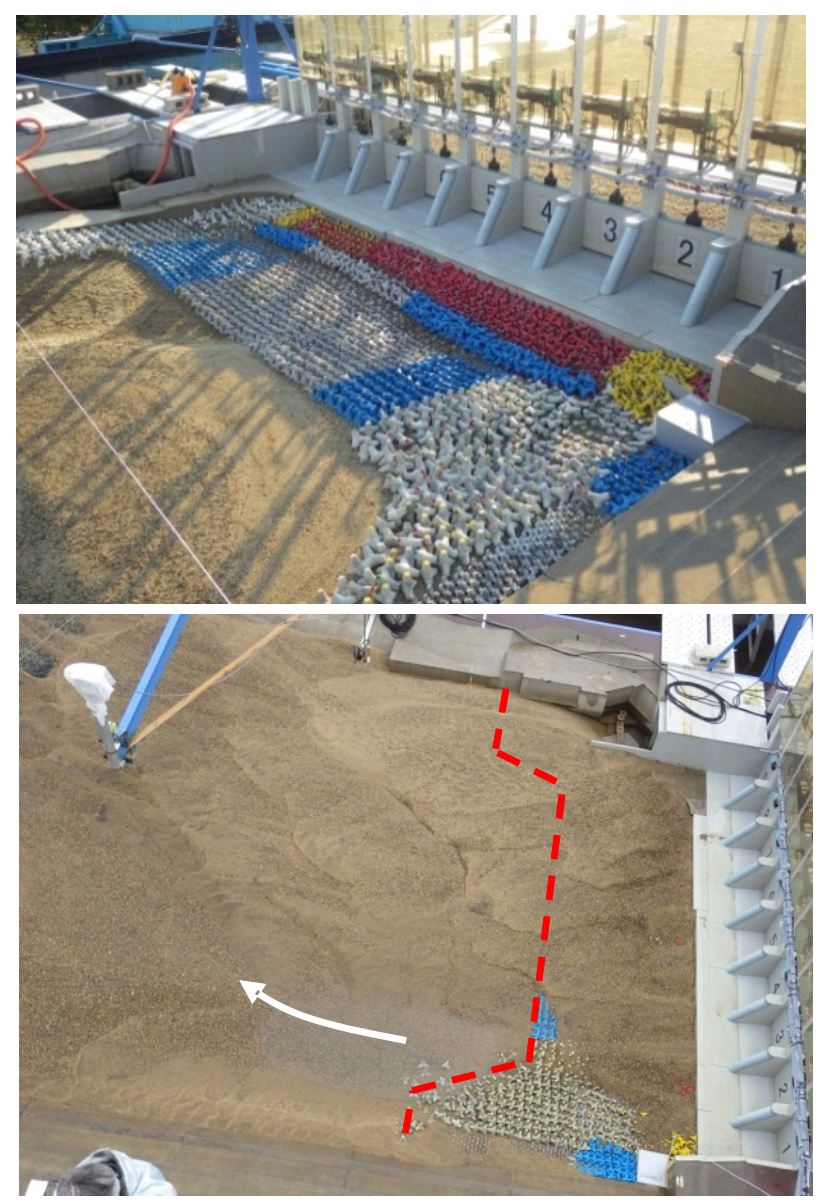

Figure 18. Stability of maintenance plan after design flood 
In the experiments with a design flood, sand was deposited along the right bank. Both mitigation plans showed some morphological changes in the consolidation blocks placed along the left bank. The riverbed maintenance plan showed a larger degree of morphological change, lowering the height of the riverbed around the river wall block foundation. Therefore, it was determined that the riverbed maintenance plan was not capable of preserving the structural integrity of the river wall.

Even though the riverbed maintenance plan showed a superior effect in reducing the amount of water discharged from the gates, this plan also showed instability in hydraulic jump positions due to sand deposits along the right bank, lowering this discharge reduction along with the hydraulic jump positions shifted upstream and downstream, and causing the water flow to accelerate at a high velocity.

The results of the experiments pointed out, for both the riverbed recovery plan and the riverbed maintenance plan, that sediments were deposited along the right bank, creating a water passage along the left bank, and morphological changes occurred in the implemented consolidation blocks. To respond to these issues, we have to remove the deposits and to reinforce the blocks that are subjected to morphological changes by this water flow. Figure 19 shows the latest long-term measure design.

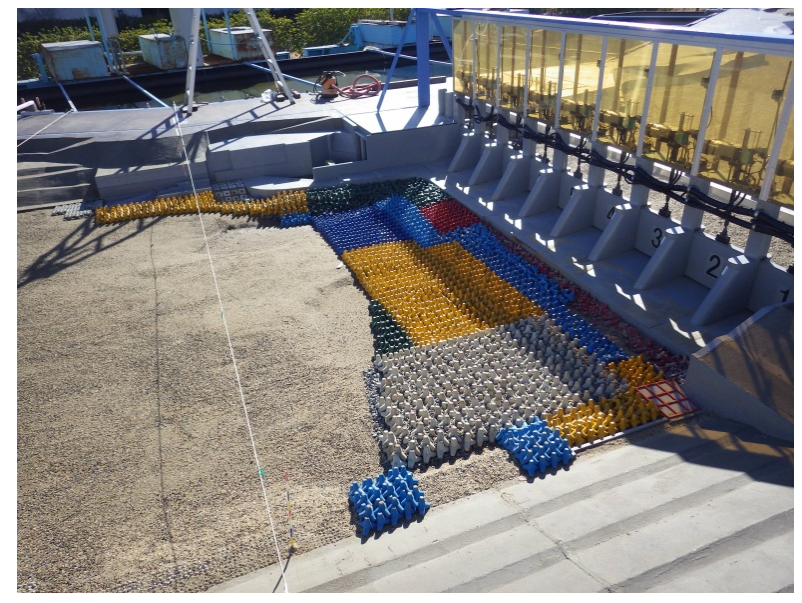

Figure 19. The latest long-term measure at Funagira Dam

\subsection{Maintenance of long-term measures}

For the riverbed maintenance plan, there is an essential issue: reduction of the structural integrity of the river wall. The issue arises if the height of the riverbed around the river wall foundation cannot be stabilized by the consolidation blocks placed along the left bank, due to sediment deposits on the right bank, lowering the amount of water flowing along the right bank, and thus resulting in faster flow velocities. Then, field observations of morphological changes will be important. Figure 20 shows the morphological change of the riverbed in front of Funagi- ra Dam after starting the full-gate equivalent procedure of water discharge on June 2014.

The maintenance plan has finally been chosen as long-term measure because of the shorter construction period. The construction has started in October 2015 (Figure 21 and Figure 22) and it will be finished in May 2018.

To comply with this measure, we have to take some additional measures including, (1) establishment of management standards stipulating those including allowable amount of sediment to be deposited along the right bank, the height of the riverbed around the river wall along the left bank, and allowable morphological changes in the river wall itself, as well as implementation of regular inspections based on management standards, (2) thorough controls of the riverbed and river wall downstream of the dam by taking measures including removal of sediment excessively built-up along the right bank and supply of sediment around the river wall on the left bank if the height of the riverbed is lowered, and (3) reinforcement of the river walls on the left and right banks by increasing the width of the consolidation work.
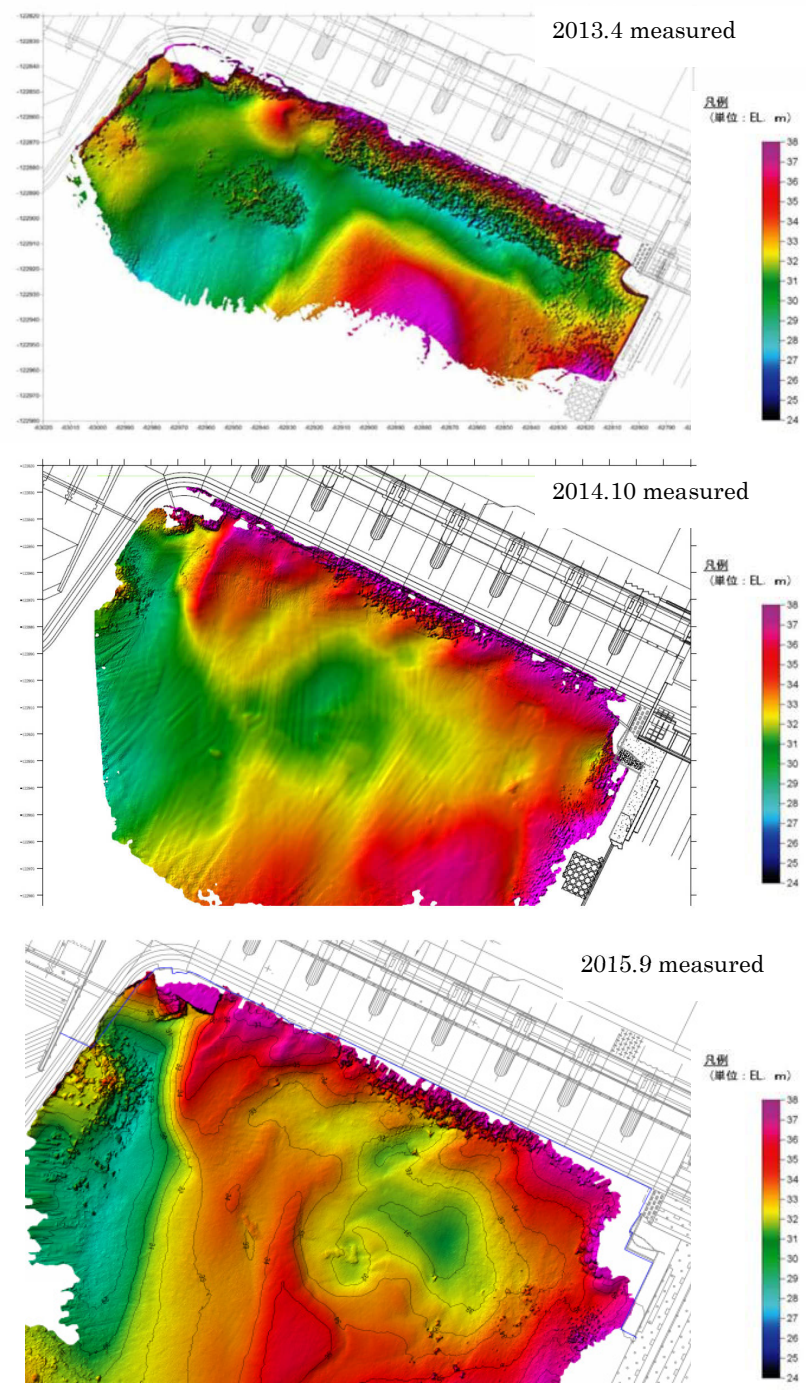

Figure 20. Field observation of morphological changes, measurement with multi-beam sonar 


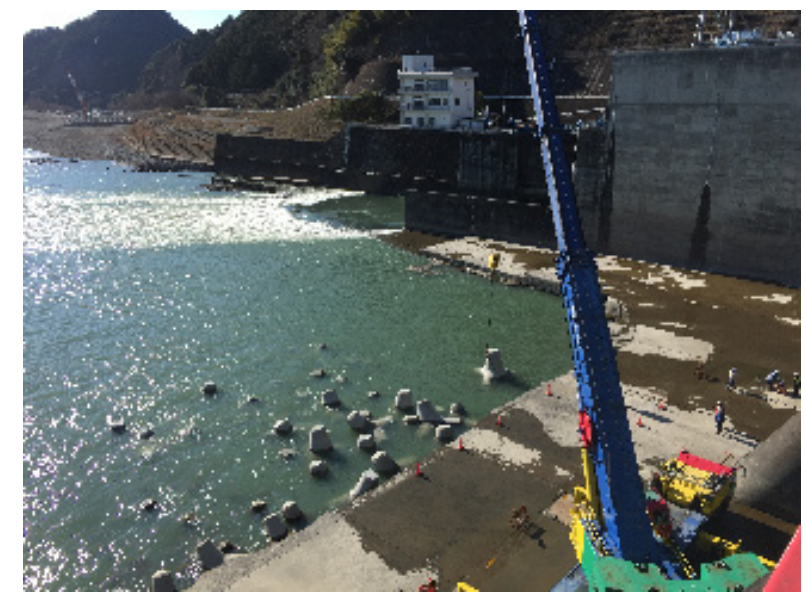

Figure 21. View of construction of long-term measures at left bank of Funagira Dam

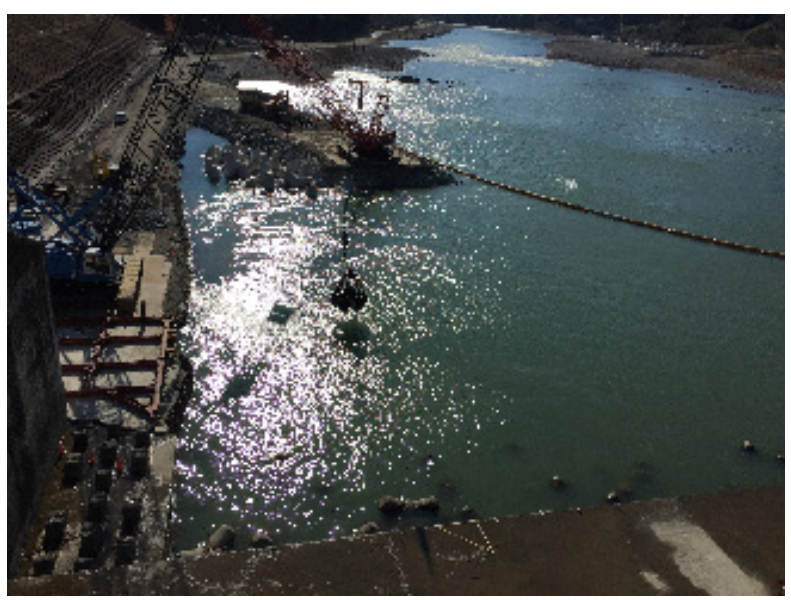

Figure 22. View of construction of long-term measures on right bank of Funagira Dam

\section{CONCLUSION}

The present paper describes the results of the investigations into the scouring phenomena that has occurred since Funagira Dam was completed, as well as describes the planned long-term measures that will be taken in the near future. To successfully implement the measures, the following points are considered important:

(1) Quick and safe measures taken to improve the soundness of the environment including the dam and the river by following the riverbed maintenance plan against the present riverbed, including: adaptation of a full-gate equivalent-type water discharge procedure, thorough implementation of planned inspections and controls, reinforcement of the consolidation work and river walls.

(2) After the measures are taken, review the necessity of further measures and their validity by evaluating longitudinal changes in the water level downstream of the river, including the work against the reduction of the water level. If there is a problem to be solved, appropriately conduct measures including drastic modifications and reinforcements.
(3) The laboratory tests indicate that the scouring was caused by the horizontal secondary swirl with non-equivalent released discharges, and by changing the types of hydraulic jump because of long-term morphological riverbed changes. The study especially indicates that severe scouring would occur not only during the extreme design discharge, but also for small discharges because of the lower water level downstream of the dam.

In addition, extra sediment will have to be supplied in an applicable range to prevent the water level downstream of the dam from being reduced, as well as to further improve the safety of the implemented consolidation work.

By utilizing the obtained information, we will focus all our efforts to securely carry out the long-term measures to stabilize the dam, to thoroughly keep and control the environment including the dam and the river, and to respond to further problems resulting from the implemented measures. This includes checks and reviews for maintenance and control standards, plans, and countermeasures. It is appropriate to examine new topics through the hydraulic scale model tests during construction and maintenance. In the future, further model tests on the maintenance program should be available.

\section{REFERENCES}

J-POWER (1972). Hydraulic scale model test of Funagira Dam and hydraulic structures for power station outlet and Tenryu river irrigation intake structures. Chigasaki institute report.

J-POWER (1977). Hydraulic scale model test of Funagira Dam and hydraulic structures for groyne structures. Chigasaki institute report.

J-POWER (1977). Hydraulic scale model test of Funagira Dam and hydraulic structures for flow condition at the left bank of downstream of dam dissipation of dam apron. Chigasaki institute report.

J-POWER (1977). Hydraulic scale model test of Funagira Dam and hydraulic structures for influence of flow condition and morphological change up and downstream of dam. Chigasaki institute report.

J-POWER (1990). Hydraulic scale model test of Funagira Dam for scouring measures downstream of dam. Chigasaki institute report.

Suga S. (1990). Hydraulic scale model test. Sankaido.

Breusers H.N.C. \& Raudkivi A.J. (1991). Scouring. Hydraulic structures design manual IAHR.

JSCE (1999). Collection of hydraulics formulas. Hydraulic committee JSCE.

J-POWER (2015). Report on scouring of Funagira Dam downstream. J-POWER \& Technical review board.

J-POWER (2015). Report on measures for scouring of Funagira Dam downstream, stability of long-term measures. $J$ POWER \& Follow-up committee. 